\title{
CONTAMINACIÓN DE PARQUES PÚBLICOS CON HUEVOS DE Toxocara spp. EN LOS DISTRITOS DE LA PROVINCIA CONSTITUCIONAL DEL CALLAO Y DEL CONO SUR DE LIMA METROPOLITANA
}

\author{
Amanda Chávez V. ${ }^{1}$, Eva Casas A. ${ }^{1}$, Junnett Cajas U. ${ }^{2}$ y José Velarde O. ${ }^{2}$
}

\section{Abstraxt}

Toxocara spp. contamination in public parks of the Constitutional Province of Callao and the southern zone of Lima was evaluated to assess the human health risk. Turf samples were collected from 176 of 479 parks ( 78 from Callao and 98 from southern Lima) using the double "W" method. Samples were processed by flotation using $\mathrm{NaCl}$ saturated solution. A sample was considered positive when at least one egg of Toxocara spp. was found. During analysis, the parks were grouped according to condition (good grass cover, moderate grass cover (around 50\% covered with grass) or poor to non-existent grass cover), as well as by the socio-economic level of the neighborhood where they were located (upper - Level I, middle - Level II, lower middle - Level III and lower - Level IV). Toxocara spp. contamination was found to be $37 \pm 11 \%$ and $30 \pm 9 \%$ for parks in Callao and southern Lima. In parks with good, moderate and poor grass cover, rates of $100 \%, 100 \%$ and $6 \%$ were found in the Callao area, compared to $42 \%, 47 \%$ and $21 \%$ in the parks of southern Lima. Evaluation of the parks according to socio-economic level revealed that in Callao, parks in levels I, II, III and IV had contamination rates of $100 \%, 48 \%, 27 \%$ and $40 \%$, while rates of $60 \%, 17 \%$ and $27 \%$ were found in the level II, III and IV parks of southern Lima. Parks with good and moderate grass cover were restricted to socioeconomic levels I and II, while parks with poor grass cover were found in level IV neighborhoods. The abundant grass cover and high humidity of well tended level I and II parks apparently explains the survival of Toxocara spp. eggs, while the poor grass cover and lack of watering in lower level parks leaves the eggs exposed to direct solar radiation leading to their destruction. Positive samples were incubated in a $2.5 \%$ potassium dichromate solution and orally inoculated in mice to verify the viability of eggs. Subsequently, migrant larva were recovered demonstrating the infective capacity of the Toxocara spp. eggs recovered during this study.

Key words: Toxocara canis, Toxascaris leonina, parks, ascarides, zoonosis.

\section{Resumen}

Se evaluó la contaminación con huevos de Toxocara spp. de parques públicos de la Provincia Constitucional del Callao y del cono sur de Lima Metropolitana para determinar el riesgo existente en salud pública de la población aledaña. Se colectaron muestras de tierra y césped en 176 de los 479 parques existentes ( 78 del Callao y 98 del cono Sur),

1 Laboratorio de Parasitología IVITA - FMV - UNMSM. E.mail: d170010@unmsm.edu.pe.

2 Práctica privada 
empleando el método de doble "W". Las muestras fueron procesadas por el método de flotación con solución sobresaturada de $\mathrm{CINa}$, considerándose positiva aquella muestra que presentara al menos un huevo de Toxocara spp. Las muestras positivas fueron incubadas en una solución de bicromato de potasio al $2.5 \%$ e inoculadas vía oral a ratones para verificar la viabilidad a los huevos. Los parques fueron categorizados según su estado de conservación en parques bien conservados (césped en toda su área), medianamente conservados (césped en cerca del 50\% del área) y mal conservados (sin césped) y según el estrato socioeconómico de la población circundante, en estratos de poder adquisitivo alto (Nivel I), medio (Nivel II), medio-bajo (Nivel III) y bajo (Nivel IV). Se encontraron prevalencias de $37 \pm 11 \%$ (promedio \pm intervalo de confianza) y $30 \pm 9 \%$ para las zonas del Callao y cono sur respectivamente. La contaminación de los parques, bien, medianamente y mal conservados fue de $100 ; 100$ y $6 \%$ respectivamente para el Callao, en tanto que para el cono sur fue de $42 ; 47$ y $21 \%$ respectivamente. Asimismo, se registró una contaminación de $100,48,27$ y $40 \%$ en parques de nivel económico I, II, III y IV del Callao, respectivamente; en tanto que en el cono sur fue de $60 ; 17$ y $27 \%$ en los niveles II, III y IV, respectivamente. Los parques bien y medianamente conservados coinciden con los parques de nivel I y II, en tanto que los parques mal conservados corresponden al nivel IV. La abundante vegetación y humedad existente en los parques bien manejados podría favorecer la conservación de los huevos de Toxocara spp. lo que explicaría los resultados encontrados. Asimismo, la carencia de huevos de Toxocara spp. en los parques mal conservados se debería a la acción directa de los rayos solares sobre los huevos. Por último, los huevos inoculados en ratones desarrollaron larvas migrantes indicando que estos huevos son potencialmente infectivos.

Palabras Clave: Toxocara canis, Toxascaris leonina, parques, ascáridos, zoonosis.

\section{Introinteión}

La contaminación de los parques públicos con heces de perros infectados por Toxocara spp. es un problema de importancia en salud pública. Gran cantidad de huevos son diseminados por perros parasitados, que bajo condiciones ambientales favorables se hacen infectivos, generando focos de contaminación ambiental. Estos focos pueden ser responsables de la presentación de la toxocariosis ocular y el síndrome de larva migrante visceral, especialmente en los niños que constituyen el grupo de mayor riesgo. La infección ocurre al ingerir huevos infectivos del parásito.

Estudios sobre contaminación en parques realizados en otros países muestran resultados diferentes, así, en Cuba y Argentina se hallaron prevalencias de 18 y $20 \%$ respectivamente, mientras que en Japón y Gran Bretaña se obtuvieron 63 y $24 \%$ res- pectivamente (Dumenico y Gálvez, 1995; Chamorro et al., 1995; Shimizu, 1993; Chieffi y Mueller, 1976)

En el Perú se han realizado algunos estudios acerca de la contaminación de parques con huevos de Toxocara spp. y áreas de juegos infantiles. Guerrero (1975) encontró una prevalencia de $24 \%$ de parques públicos contaminados en Lima Metropolitana y Buitrón (1976) reportó el 56\% de parques contaminados con huevos de Toxocara spp. en el área urbana de Paramonga.

Este estudio constituyen parte de un programa que se viene ejecutando en los diferentes parques de Lima Metropolitana y Callao a fin de tener datos completos sobre la prevalencia de huevos de Toxocara spp en parques públicos, así como determinar el riesgo existente para la salud pública de la población limeña y del Callao. 


\section{Niterviles y Mrtwos}

\section{Localidades}

El estudio fue realizado en los distritos de Ventanilla, Bellavista, Callao, Carmen de la Legua Reynoso, La Perla y La Punta de la Provincia Constitucional del Callao y en los distritos de San Juan de Miraflores, Villa María del Triunfo, VillaEl Salvador y Chorrillos, correspondientes al Cono Sur de Lima Metropolitana.

El estudio se efectuó entre los meses de diciembre de 1998 y marzo de 1999. En la Provincia Constitucional del Callao se presentó una variación de temperatura y humedad de 18.8 a $27.0^{\circ} \mathrm{C}$ y de 86 a $94 \%$, respectivamente (Marina de Guerra del Perú, 1998); mientras que en los distritos del Cono Sur la temperatura fue entre 17.3 y $26.3^{\circ} \mathrm{C}$ con una humedad relativa media de $82 \%$ (SENAMHI, 1999).

\section{Metodología}

Se colectaron entre 3 y $5 \mathrm{~kg}$ de tierra y césped de cada uno de los parques mediante la técnica de la doble W.

Las muestras fueron procesadas por el método de flotación con solución sobresaturada de cloruro de sodio, considerándose positiva aquella muestra que presentara al menos un huevo de Toxocara spp.

Los parques fueron agrupados y clasificados de acuerdo al estado de conservación y al estrato socio económico del distrito. La clasificación en base al estado de conservación fue: Parques bien conservados (césped en todo el área), medianamente conservados (césped en cerca del $50 \%$ del área) y mal conservados o baldíos (sin césped). Los lineamientos para la clasificación según estrato socio económico, se hizo en base a las directivas del Instituto Nacional de Estadística e Informática (INEI, 1998): Estrato socio económico alto (Nivel I), medio (Nivel II), medio-bajo (Nivel III) y bajo (Nivel IV). Además, se verificó la viabilidad de los huevos de Toxocara spp. obtenidos en el análisis de flotación; éstos, fueron incubados en una solución de bicromato de potasio al $2.5 \%$ por 7 a 15 días con el fin de obtener huevos larvados. Los huevos ( $\mathrm{n}=140)$ fueron inoculados vía oral en 2 ratones, los que fueron sacrificados al cabo de 7 días para determinar lesiones macroscópicas e histopatológicas en órganos. Asimismo, se les tomaron muestras para procesarlas mediante la técnica de Baerman para la obtención de larvas migrantes.

\section{Tamaño de muestra}

El tamaño de la muestra se determinó con la fórmula de proporciones para poblaciones finitas (Daniel, 1996). Se obtuvo un tamaño muestral de 78 parques para la Provincia Constitucional del Callao y 98 parques para el Cono Sur de Lima Metropolitana. El número de parques por distrito se determinó en forma proporcional al número total de parques de la zona en estudio, realizándose la selección de los parques en forma aleatoria.

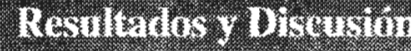

El 37.0\% (29/78) de los parques de la Provincia Constitucional del Callao y el $30 \%$ (29/98) de los parques del Cono Sur de Lima Metropolitana se encontraron contaminados con huevos de Toxocara spp. Los distritos de La Punta, Bellavista y Ventanilla en el primer caso, y el distrito de Chorrillos en el segundo, presentaron prevalencias de contaminación superiores al $40 \%$ (Cuadros l y 2). 
Contaminación de parques públicos con Toxocara spp.

Cuadro 1. Porcentaje de parques positivos a huevos de Toxocara spp en los distritos de la Provincia Constitucional del Callao.

\begin{tabular}{lccc}
\hline Distritos & $\begin{array}{c}\text { Parques } \\
\text { muestreados, } \mathbf{n}\end{array}$ & $\begin{array}{c}\text { Parques } \\
\text { contaminados, } \mathbf{n}\end{array}$ & $\begin{array}{c}\text { Parques positivos, } \\
\%\end{array}$ \\
\hline Bellavista & 21 & 10 & 48 \\
Callao & 29 & 10 & 34 \\
Carmen de la Legua & 3 & 1 & 33 \\
La Perla & 15 & 2 & 13 \\
La Punta & 3 & 3 & 100 \\
Ventanilla & 7 & 3 & 43 \\
\hline Total & 78 & 29 & $37 \% \pm 11$ \\
\hline
\end{tabular}

Cuadro 2. Porcentaje de parques positivos a huevos de Toxocara spp. en los distritos del cono sur, Lima Metropolitana.

\begin{tabular}{lccc}
\hline Distritos del Cono Sur & $\begin{array}{c}\text { Parques } \\
\text { muestreados, } n\end{array}$ & $\begin{array}{c}\text { Parques } \\
\text { contaminados, } n\end{array}$ & $\begin{array}{c}\text { Parques } \\
\text { Positivos, \% }\end{array}$ \\
\hline Villa el Salvador & 26 & 7 & 27 \\
Villa María del Triunfo & 32 & 8 & 25 \\
San Juan de Miraflores & 26 & 8 & 31 \\
Chorrillos & 14 & 6 & 43 \\
\hline Total & 98 & 29 & $30 \% \pm 9$ \\
\hline
\end{tabular}

En relación con el estado de conservación de los parques se encontró que el mayor porcentaje de parques positivos corresponde a los bien y medianamente conservados en tanto que los parques mal conservados o baldíos son los menos contaminados (Cuadro 3).

Estos resultados se atribuyen al hecho que los parques medianamente conservados y bien conservados tienen abundantes áreas de vegetación, de modo que reúnen las condiciones necesarias como humedad y microclimas favorables para el desarrollo y conservación de los huevos de Toxocara spp en la superficie del terreno por mucho tiempo. Los huevos de estos parásitos, desarrollan mal y se destruyen en poco tiempo en parques baldíos con terrenos arenosos, debido a que están más expuestos a la acción de los rayos solares y sin la humedad necesaria para su conservación.

En relación al estrato socio económico, se encontró que los niveles I y II tuvieron los mayores porcentaje de parques contaminados con huevos de Toxocara spp, en tanto que el menor grado de contaminación ocurrió en el Nivel III (Cuadro 4).

En los niveles I y II se obtuvieron los mayores porcentajes de parques positivos, debido a que en esos distritos, los parques 
Cuadro 3. Porcentaje de parques positivos a huevos de Toxocara spp. según el estado de conservación de los parques.

\begin{tabular}{|c|c|c|c|c|}
\hline \multirow[t]{3}{*}{ Estado de Parques } & \multicolumn{4}{|c|}{ Área Geográfica } \\
\hline & \multicolumn{2}{|c|}{ Prov. del Callao } & \multicolumn{2}{|c|}{ Cono Norte } \\
\hline & $\mathbf{n}$ & $\begin{array}{c}\text { Parques } \\
\text { Positivos, } \%\end{array}$ & $\mathbf{n}$ & $\begin{array}{c}\text { Parques } \\
\text { Positivos, } \%\end{array}$ \\
\hline Bien conservados & 11 & 100 & 19 & 42 \\
\hline Medianamente conservados & 15 & 100 & 17 & 47 \\
\hline Mal conservados & 52 & 6 & 62 & 21 \\
\hline
\end{tabular}

Cuadro 4. Porcentaje de parques positivos a huevos de Toxocara spp. de acuerdo al estado socio económico.

\begin{tabular}{|c|c|c|c|c|c|c|}
\hline \multirow[b]{2}{*}{ Estratos* } & \multicolumn{3}{|c|}{ Provincia del Callao } & \multicolumn{3}{|c|}{ Cono Sur } \\
\hline & Distritos & $\begin{array}{c}\text { Parques } \\
\text { Evaluados, } \\
\mathrm{n} \\
\end{array}$ & $\begin{array}{c}\text { Parques } \\
\text { positivos, } \\
\% \\
\end{array}$ & Distritos & $\begin{array}{l}\text { Parques } \\
\text { evaluados }\end{array}$ & $\begin{array}{c}\text { Parques } \\
\text { positivos, } \\
\% \\
\end{array}$ \\
\hline Nivel I & La Punta & 3 & 100 & $\ldots * *$ & & \\
\hline Nivel II & Bellavista & 21 & 48 & $\begin{array}{l}\text { Chorrillos } \\
\text { S.J. de Miraflores } \\
\text { V.M. del Triunfo }\end{array}$ & $\begin{array}{l}5 \\
7 \\
3\end{array}$ & 60 \\
\hline Nivel III & $\begin{array}{l}\text { Callao } \\
\text { La Perla }\end{array}$ & $\begin{array}{l}29 \\
15\end{array}$ & 27 & $\begin{array}{l}\text { Chorrillos } \\
\text { S.J. de Miraflores } \\
\text { V. El Salvador } \\
\text { V.M. del Triunfo }\end{array}$ & $\begin{array}{l}3 \\
5 \\
6 \\
9\end{array}$ & 17 \\
\hline Nivel IV & $\begin{array}{l}\text { C. de la } \\
\text { Legua } \\
\text { Ventanilla }\end{array}$ & $\begin{array}{l}3 \\
7\end{array}$ & 40 & $\begin{array}{l}\text { Chorrillos } \\
\text { S.J. de Miraflores } \\
\text { V. El Salvador } \\
\text { V.M. del Triunfo }\end{array}$ & $\begin{array}{c}6 \\
14 \\
20 \\
20\end{array}$ & 27 \\
\hline
\end{tabular}

* Fuente: Instituto Nacional de Estadística e Informática (INEL), 1998.

* El INEI no identifica áreas con estrato socio económico alto en el Cono Sur.

se encuentran bien o medianamente conservados. Estas áreas constituyen lugares predilectos para llevar a los perros a ejercitar y realizar sus deposiciones. Aquellos animales que se encuentren parasitados causarán la contaminación del parque, que aunado a las condiciones favorables del suelo (humedad, sombra), contribuirán a la persistencia de la contaminación de estas áreas. En el estrato socioeconómico bajo, a pesar que el terreno de estos parques no son los adecuados para el desarrollo del parásito, se pudo encontrar huevos de Toxocara spp, debido posiblemente a la elevada población canina y al alto nivel de parasitismo, aunado a la escasez de recursos económicos de la población de este estrato. 
Se comprobó la viabilidad de los huevos de Toxocara spp aislados de las dos áreas en estudio, al aislar larvas migrantes en hígado y pulmones de los ratones inoculados. Así mismo, se observaron lesiones de una infección de tipo aguda en los cortes histopatológicos.

\section{Becommulaciures:}

- Promover campañas de educación sanitaria, especialmente en la población de edad escolar, recomendando desparasitaciones periódicas y el mantenimiento de las reglas básicas de higiene.

- Alertar a las autoridades sanitarias y municipales sobre el peligro inminente que representa esta zoonosis.

- Prohibir y sancionar a los propietarios de canes que utilicen los parques públicos como letrinas para deposición de sus perros.

- Realizar un control poblacional de perros y gatos vagabundos.

\section{Viteratmat Cheth}

1. Buitrón, L.A. 1976. Estudio de la contaminación de áreas de uso público con huevos de Toxocara spp en el área urbana de Paramonga - distrito de Pativilca - provincia de Chancay - departamento de Lima. Tesis bachiller. FMV - UNMSM. 25 p.

2. Chamorro, M.; M. Stein y J.M. Alonso. 1995. Contaminación de plazas públicas de Resistencia (Argentina) con huevos de Toxocara spp. Rev. Soc. Chil. Parasitol 19 (360).

4. Chieffi, P.P. y E.E. Mueller. 1976. Prevalencia de parasitismo por Toxocara canis en câes e presença de ovos de Toxocara sp. no solo de localidade públicas da zona urbana do município de Londrina, estado de Paraná, Brasil. Rev. Saúde Públic Sao Paulo, 10:367-372.

5. Daniel, W. 1996. Bioestadística. Base para el análisis de las ciencias de la salud. 3ra. Ed., p.206. Editorial Limusa S.A. México.

6. Dumenico, B. y D. Gálvez. 1995. Soil contamination in Habana city with Toxocara canis eggs. Rev. Cubana Med. Trop. 47(3): 178-180.

7. Guerrero, M.O. 1975. Estudio de la contaminación de parques públicos de Lima Metropolitana con huevos de Toxocara spp. Tesis Médico Veterinario. FMV- UNMSM. Lima-Perú. 12 p.

8. Instituto Nacional de Estadística e Informática (INEI). 1998. Planos estratificados de Lima Metropolitana a nivel de manzana, según estrato socioeconómico de los hogares. INEI. Mosaic marking. $150 \mathrm{p}$.

9. Marina de Gerra del Perú. 1998. Dirección de Hidrografía y Navegación. Chucuito - Callao.

8. Servicio Nacional de Meterología e Hidrología (SENAMHI). 1999. Instituto de donde se obtuvo la información climática de los distritos del Cono Sur correspondiente al período diciembre 1998 - marzo 1999.

9. Shimizu, T. 1993. Prevalence of Toxocara eggs in sandpits in Tokushima city and its outskirts. J. Vet. Med. Sci. 55(5): 807-811. 